\title{
Cancer Statistics in Korea: Incidence, Mortality, Survival and Prevalence in 2010
}

\section{Kyu-Won Jung, MS ${ }^{1}$ \\ Young-Joo Won, PhD' \\ Hyun-Joo Kong, MS' \\ Chang-Mo Oh, MD \\ Hong Gwan Seo, MD, PhD² \\ Jin-Soo Lee, MD, PhD ${ }^{1}$}

${ }^{1}$ The Korea Central Cancer Registry, Division of Cancer Registration and Surveillance,

${ }^{2}$ National Cancer Control Institute, National Cancer Center, Goyang, Korea

\section{Purpose}

This article gives an overview of nationwide cancer statistics, including incidence, mortality, survival and prevalence, and their trends in Korea based on 2010 cancer incidence data.

\section{Materials and Methods}

Incidence data from 1993 to 2010 were obtained from the Korea National Cancer Incidence Database, and vital status was followed until 31 December 2011. Mortality data from 1983 to 2010 were obtained from Statistics Korea. Crude and agestandardized rates for incidence, mortality, prevalence, and relative survival were calculated.

\section{Results}

In total, 202,053 cancer cases and 72,046 cancer deaths occurred during 2010, and 960,654 prevalent cancer cases were identified in Korea as of 1 January 2011. The incidence of all cancers combined showed an annual increase of 3.3\% from 1999 to 2010. The incidences of liver and cervical cancers have decreased while those of thyroid, breast, prostate and colorectal cancers have increased. Notably, thyroid cancer, which is the most common cancer in Korea, increased by $24.2 \%$ per year rapidly in both sexes. The mortality of all cancers combined showed a decrease by $2.7 \%$ annually from 2002 to 2010 . Five-year relative survival rates of patients who were diagnosed with cancer from 2006 to 2011 had improved by $22.9 \%$ compared with those from 1993 to1995.

\section{Conclusion}

While the overall cancer incidence in Korea has increased rapidly, age-standardized cancer mortality rates have declined since 2002 and survival has improved.

Central Cancer Registry,

Division of Cancer Registration and

Surveillance, National Cancer Center,

323 Ilsan-ro, Ilsandong-gu,

Goyang 410-769, Korea

Tel: 82-31-920-2015

Fax: 82-31-920-2179

E-mail: astra67@ncc.re.kr

Received February 26, 2013

Accepted February 27, 2013
Key words

Incidence, Mortality, Survival, Prevalence, Neoplasms, Korea

\section{Introduction}

Cancer has been the leading cause of death in Korea since 1983 [1] and is associated with the largest disease burden [2]. More than 190,000 new cancer cases are diagnosed annually in Korea, and one in four deaths results from cancer $[3,4]$. This article provides an overview of nationwide cancer statistics, including the incidence, mortality, prevalence and survival rates, and their trends.

\section{Data sources}

The Ministry of Health and Welfare, Korea, initiated a nationwide hospital-based cancer registry called the Korea Central Cancer Registry (KCCR) as early as 1980. The registry collected $80-90 \%$ of cancer cases annually from more than 180 training hospitals throughout the country. In 1999, the KCCR expanded cancer registration to cover the entire population under the Population-Based Regional Cancer Registry program. Details of the history, objectives and 
activities of the KCCR have been documented [5]. Incidence data from 1999 to 2010 were obtained from the Korea National Cancer Incidence Database (KNCI DB). The completeness of incidence data for 2010 was $97.1 \%$, as determined by the Ajiki method [6].

Cancer cases were classified according to the International Classification of Diseases for Oncology, 3rd edition [7] and converted according to the International Classification of Diseases, 10th edition (ICD-10) [8]. The survival analysis used 1,992,568 cancer cases first diagnosed during 1993-2010 from the KNCI DB, and followed vital status until 31 December 2011.

Mortality data from 1983-2010 were obtained from Statistics Korea [1]. Cause of death was coded and classified according to ICD-10. Population data were also obtained from Statistics Korea using the resident registration popula- tion on July 1 of specified years.

\section{Analysis}

Crude rates (CRs) and age-specific rates of cancer incidence and mortality were calculated. Age-standardized rates (ASRs) were determined using the world standard population [9]. Cumulative risks of cancer, which represent the probability of developing cancer during one's lifetime, were also calculated. Changes in the annual ASRs of cancer incidence were examined by calculating the annual percentage change over a time period as $(\exp (b)-1) \times 100$, where $b$ is the slope of the regression of $\log$ ASR for a given calendar year [10].

Prevalence was also calculated to assess the cancer burden, which reflects new and pre-existing cancer patients diag-

Table 1. Numbers of incident cancer cases, deaths, and prevalent cancer cases during 2010 in Korea by sex

\begin{tabular}{|c|c|c|c|c|c|c|c|c|c|}
\hline \multirow{2}{*}{ Site/Type } & \multicolumn{3}{|c|}{ New cases } & \multicolumn{3}{|c|}{ Deaths } & \multicolumn{3}{|c|}{ Prevalent cases $^{\text {a) }}$} \\
\hline & Both & Male & Female & Both & Male & Female & Both & Male & Female \\
\hline All sites & 202,053 & 103,014 & 99,039 & 72,046 & 45,209 & 26,837 & 960,654 & 434,365 & 526,289 \\
\hline $\begin{array}{l}\text { Lip, oral cavity } \\
\text { and pharynx }\end{array}$ & 2,695 & 1,916 & 779 & 963 & 742 & 221 & 13,961 & 9,464 & 4,497 \\
\hline Esophagus & 2,199 & 2,017 & 182 & 1,352 & 1,254 & 98 & 6,303 & 5,689 & 614 \\
\hline Stomach & 30,092 & 20,179 & 9,913 & 10,032 & 6,512 & 3,520 & 169,868 & 112,811 & 57,057 \\
\hline Colon and rectum & 25,782 & 15,612 & 10,170 & 7,645 & 4,322 & 3,323 & 136,055 & 80,717 & 55,338 \\
\hline Liver & 15,921 & 11,818 & 4,103 & 11,205 & 8,350 & 2,855 & 43,351 & 32,542 & 10,809 \\
\hline Gallbladder ${ }^{\mathrm{b})}$ & 4,877 & 2,532 & 2,345 & 3,502 & 1,758 & 1,744 & 12,349 & 6,337 & 6,012 \\
\hline Pancreas & 4,637 & 2,505 & 2,132 & 4,306 & 2,323 & 1,983 & 5,583 & 3,052 & 2,531 \\
\hline Larynx & 1,144 & 1,071 & 73 & 416 & 383 & 33 & 7,583 & 7,120 & 463 \\
\hline Lung & 20,711 & 14,650 & 6,061 & 15,623 & 11,416 & 4,207 & 43,564 & 28,784 & 14,780 \\
\hline Breast & 14,277 & 69 & 14,208 & 1,868 & 10 & 1,858 & 103,418 & 472 & 102,946 \\
\hline Cervix uteri & 3,857 & - & 3,857 & 956 & - & 956 & 38,488 & - & 38,488 \\
\hline Corpus uteri & 1,752 & - & 1,752 & 222 & - & 222 & 11,935 & - & 11,935 \\
\hline Ovary & 1,981 & - & 1,981 & 895 & - & 895 & 11,782 & - & 11,782 \\
\hline Prostate & 7,848 & 7,848 & - & 1,328 & 1,328 & - & 35,372 & 35,372 & - \\
\hline Testis & 206 & 206 & - & 9 & 9 & - & 1,774 & 1,774 & - \\
\hline Kidney & 3,598 & 2,520 & 1,078 & 797 & 562 & 235 & 20,203 & 13,639 & 6,564 \\
\hline Bladder & 3,415 & 2,752 & 663 & 1,100 & 822 & 278 & 21,921 & 17,823 & 4,098 \\
\hline Brain and $\mathrm{CNS}$ & 1,715 & 922 & 793 & 1,182 & 645 & 537 & 7,527 & 3,951 & 3,576 \\
\hline Thyroid & 36,021 & 6,231 & 29,790 & 356 & 94 & 262 & 174,918 & 26,264 & 148,654 \\
\hline Hodgkin lymphoma & 243 & 167 & 76 & 48 & 30 & 18 & 1,609 & 1,035 & 574 \\
\hline $\begin{array}{l}\text { Non-Hodgkin } \\
\text { lymphoma }\end{array}$ & 3,940 & 2,171 & 1,769 & 1,457 & 817 & 640 & 20,838 & 11,394 & 9,444 \\
\hline Multiple myeloma & 1,070 & 563 & 507 & 763 & 399 & 364 & 3,073 & 1,624 & 1,449 \\
\hline Leukemia & 2,684 & 1,540 & 1,144 & 1,618 & 922 & 696 & 12,287 & 6,793 & 5,494 \\
\hline Other and ill-defined & 11,388 & 5,725 & 5,663 & 4,403 & 2,511 & 1,892 & 56,892 & 27,708 & 29,184 \\
\hline
\end{tabular}

CNS, central nervous system. ${ }^{a}$ Limited-duration prevalent cases on January 1, 2011. These are patients who were diagnosed between January 1, 1999 and December 31, 2010 and who were known alive on January 1, 2011. Multiple

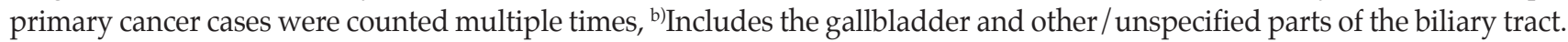


nosed during a given period of time still alive on an index date. Using cancer incidence database data from 1999 to 2010, we defined prevalent cases on January 1, 2011 as patients who were diagnosed between January 1, 1999 and December 31, 2010 and who were alive on January 1, 2011. We calculated limited-duration prevalences, such as the 1- and 5-year prevalences. For example, the 5-year prevalence was calculated as the number of people alive on January 1, 2011 who had been diagnosed with cancer within the previous 5 years. We applied this counting method using the SEER *Stat software [11] to calculate the number of cases, while adjusting for patients lost to follow-up [10].

The survival duration for each case was determined as the interval between the date of initial diagnosis and the date of death, date of loss to follow-up, or closing date for followup. Observed survival rates were calculated using the life-table method and relative survival rates by the Ederer II method [12] using an algorithm written in SAS by Dickman [13], with some minor modifications.

\section{Selected Findings}

\section{Incidence}

Table 1 presents the overall number of incident cancer cases, deaths, and prevalent cases during 2010 in Korea by sex and cancer site. In 2010, 202,053 incident cancer cases and 72,046 deaths were identified. As of 1 January 2011, 960,654 prevalent cancer cases diagnosed between 1999 and 2010 were identified. In 2010, the cumulative risk of developing cancer during one's lifetime was $37.6 \%$ for males and $33.3 \%$ for females.

Table 2 shows cancer incidence rates in 2010 by sex. The CRs of all sites combined in 2010 were 412.4 and 397.7 per 100,000 in males and females, respectively. The ASRs of all sites combined were 324.1 and 268.7 per 100,000 in males and females, respectively. In males, the five leading primary cancer sites were the stomach (CR, 80.8; ASR, 62.3), colon and

Table 2. Crude and age-standardized cancer incidence rates during 2010 in Korea by sex

\begin{tabular}{|c|c|c|c|c|c|c|}
\hline \multirow[t]{2}{*}{ Site/Type } & \multicolumn{3}{|c|}{ Crude incidence rate per 100,000} & \multicolumn{3}{|c|}{$\begin{array}{l}\text { Age-standardized incidence rate } \\
\text { per } 100,000^{\mathrm{a})}\end{array}$} \\
\hline & Both & Male & Female & Both & Male & Female \\
\hline All sites & 405.1 & 412.4 & 397.7 & 286.4 & 324.1 & 268.7 \\
\hline Lip, oral cavity, and pharynx & 5.4 & 7.7 & 3.1 & 3.9 & 5.9 & 2.1 \\
\hline Esophagus & 4.4 & 8.1 & 0.7 & 3.1 & 6.4 & 0.4 \\
\hline Stomach & 60.3 & 80.8 & 39.8 & 41.8 & 62.3 & 24.9 \\
\hline Colon and rectum & 51.7 & 62.5 & 40.8 & 35.9 & 48.6 & 25.3 \\
\hline Liver & 31.9 & 47.3 & 16.5 & 22.3 & 36.0 & 10.2 \\
\hline Gallbladder $^{\mathrm{b})}$ & 9.8 & 10.1 & 9.4 & 6.5 & 8.1 & 5.4 \\
\hline Pancreas & 9.3 & 10.0 & 8.6 & 6.3 & 7.9 & 4.9 \\
\hline Larynx & 2.3 & 4.3 & 0.3 & 1.6 & 3.4 & 0.2 \\
\hline Lung & 41.5 & 58.7 & 24.3 & 28.0 & 46.5 & 14.3 \\
\hline Breast & 28.6 & 0.3 & 57.1 & 20.2 & 0.2 & 39.8 \\
\hline Cervix uteri & 7.7 & - & 15.5 & 5.5 & - & 10.6 \\
\hline Corpus uteri & 3.5 & - & 7.0 & 2.5 & - & 5.0 \\
\hline Ovary & 4.0 & - & 8.0 & 2.9 & - & 5.7 \\
\hline Prostate & 15.7 & 31.4 & - & 10.7 & 25.3 & - \\
\hline Testis & 0.4 & 0.8 & - & 0.4 & 0.8 & - \\
\hline Kidney & 7.2 & 10.1 & 4.3 & 5.2 & 7.8 & 3.0 \\
\hline Bladder & 6.8 & 11.0 & 2.7 & 4.6 & 8.7 & 1.5 \\
\hline Brain and CNS & 3.4 & 3.7 & 3.2 & 3.0 & 3.4 & 2.6 \\
\hline Thyroid & 72.2 & 24.9 & 119.6 & 52.7 & 18.3 & 87.4 \\
\hline Hodgkin lymphoma & 0.5 & 0.7 & 0.3 & 0.4 & 0.6 & 0.3 \\
\hline Non-Hodgkin lymphoma & 7.9 & 8.7 & 7.1 & 6.0 & 7.1 & 5.0 \\
\hline Multiple myeloma & 2.1 & 2.3 & 2.0 & 1.5 & 1.7 & 1.3 \\
\hline Leukemia & 5.4 & 6.2 & 4.6 & 5.0 & 6.0 & 4.1 \\
\hline Other and ill-defined & 22.8 & 22.9 & 22.7 & 16.7 & 19.0 & 14.9 \\
\hline
\end{tabular}

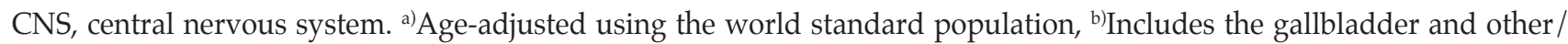
unspecified parts of the biliary tract. 
Table 3. The 10 leading causes of death in Korea during 2010

\begin{tabular}{|c|c|c|c|c|}
\hline Rank & Cause of death & No. of deaths & Deaths (\%) & $\begin{array}{l}\text { Age-standardized death rate } \\
\text { per } 100,000^{\mathrm{a}}\end{array}$ \\
\hline & All causes & 255,405 & 100.0 & 344.8 \\
\hline 1 & Cancer & 69,780 & 28.2 & 96.3 \\
\hline 2 & Cerebrovascular disease & 25,838 & 10.4 & 33.3 \\
\hline 3 & Heart disease & 22,347 & 9.2 & 30.1 \\
\hline 4 & Intentional self-harm (suicide) & 15,413 & 6.1 & 23.4 \\
\hline 5 & Diabetes mellitus & 9,757 & 4.1 & 13.1 \\
\hline 6 & Pneumonia & 7,147 & 2.9 & 9.4 \\
\hline 7 & Chronic lower respiratory diseases & 6,914 & 2.8 & 8.7 \\
\hline 8 & Disease of the liver & 6,868 & 2.7 & 9.5 \\
\hline 9 & Transport accidents & 6,324 & 2.7 & 10.8 \\
\hline \multirow[t]{2}{*}{10} & Hypertensive diseases & 4,749 & 1.9 & 6.0 \\
\hline & Others & 74,485 & 29.2 & 104.3 \\
\hline
\end{tabular}

Source: Mortality data, 2010, Statistics Korea [1]. a) Age-adjusted using the world standard population.

Table 4. Crude and age-standardized cancer mortality rates during 2010 in Korea by sex

\begin{tabular}{|c|c|c|c|c|c|c|}
\hline \multirow[t]{2}{*}{ Site/Type } & \multicolumn{3}{|c|}{ Crude mortality rate per 100,000} & \multicolumn{3}{|c|}{$\begin{array}{l}\text { Age-standardized mortality rate } \\
\text { per } 100,000^{\mathrm{a}}\end{array}$} \\
\hline & Both & Male & Female & Both & Male & Female \\
\hline All sites & 144.4 & 181.0 & 107.8 & 96.3 & 144.7 & 61.6 \\
\hline Lip, oral cavity, and pharynx & 1.9 & 3.0 & 0.9 & 1.3 & 2.3 & 0.5 \\
\hline Esophagus & 2.7 & 5.0 & 0.4 & 1.8 & 4.0 & 0.2 \\
\hline Stomach & 20.1 & 26.1 & 14.1 & 13.2 & 20.7 & 7.8 \\
\hline Colon and rectum & 15.3 & 17.3 & 13.3 & 10.1 & 14.0 & 7.3 \\
\hline Liver & 22.5 & 33.4 & 11.5 & 15.4 & 25.8 & 6.6 \\
\hline Gallbladder $^{\mathrm{b})}$ & 7.0 & 7.0 & 7.0 & 4.5 & 5.7 & 3.7 \\
\hline Pancreas & 8.6 & 9.3 & 8.0 & 5.7 & 7.4 & 4.4 \\
\hline Larynx & 0.8 & 1.5 & 0.1 & 0.5 & 1.2 & 0.1 \\
\hline Lung & 31.3 & 45.7 & 16.9 & 20.5 & 36.6 & 9.1 \\
\hline Breast & 3.7 & 0.0 & 7.5 & 2.6 & 0.0 & 5.0 \\
\hline Cervix uteri & 1.9 & - & 3.8 & 1.3 & - & 2.3 \\
\hline Corpus uteri & 0.4 & - & 0.9 & 0.3 & - & 0.6 \\
\hline Ovary & 1.8 & - & 3.6 & 1.2 & - & 2.3 \\
\hline Prostate & 2.7 & 5.3 & - & 1.6 & 4.6 & - \\
\hline Testis & 0.0 & 0.0 & - & 0.0 & 0.0 & - \\
\hline Kidney & 1.6 & 2.3 & 0.9 & 1.1 & 1.8 & 0.5 \\
\hline Bladder & 2.2 & 3.3 & 1.1 & 1.4 & 2.8 & 0.5 \\
\hline Brain and CNS & 2.4 & 2.6 & 2.2 & 1.8 & 2.2 & 1.4 \\
\hline Thyroid & 0.7 & 0.4 & 1.1 & 0.5 & 0.3 & 0.5 \\
\hline Hodgkin lymphoma & 0.1 & 0.1 & 0.1 & 0.1 & 0.1 & 0.0 \\
\hline Non-Hodgkin lymphoma & 2.9 & 3.3 & 2.6 & 2.0 & 2.6 & 1.5 \\
\hline Multiple myeloma & 1.5 & 1.6 & 1.5 & 1.0 & 1.3 & 0.8 \\
\hline Leukemia & 3.2 & 3.7 & 2.8 & 2.5 & 3.1 & 1.9 \\
\hline Other and ill-defined & 8.8 & 10.1 & 7.6 & 6.0 & 8.2 & 4.4 \\
\hline
\end{tabular}

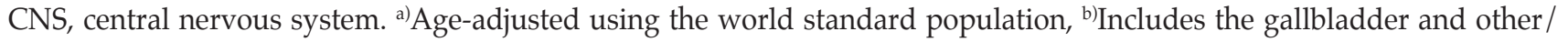
unspecified parts of the biliary tract. 
$\frac{0}{4}$

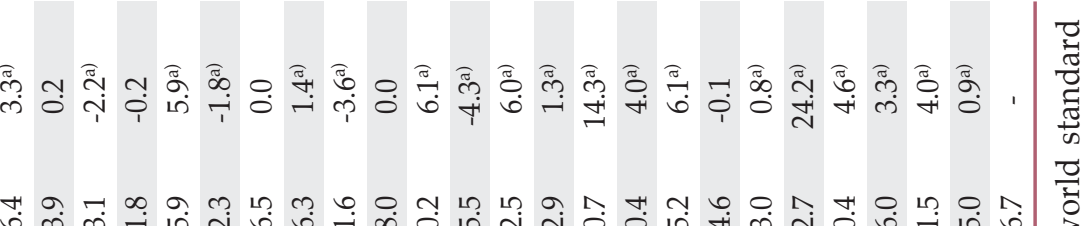

产 节

至

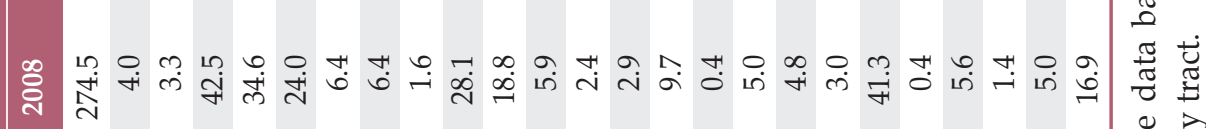

商

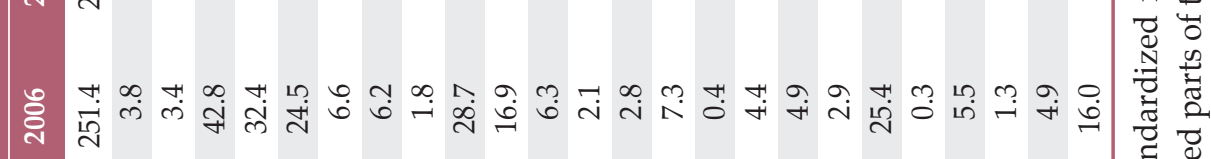

ฮ્ર

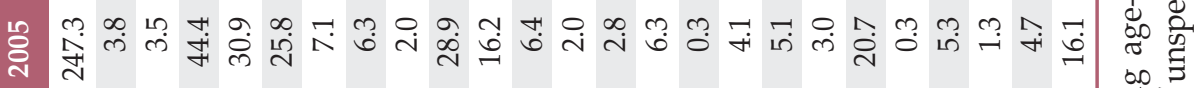

ઇ艹

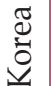

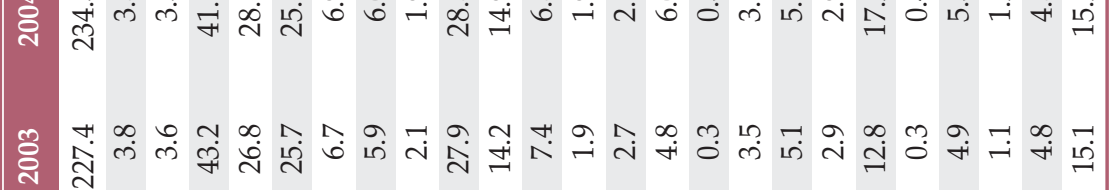

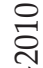

รे

(1)

:

t

岗

苛

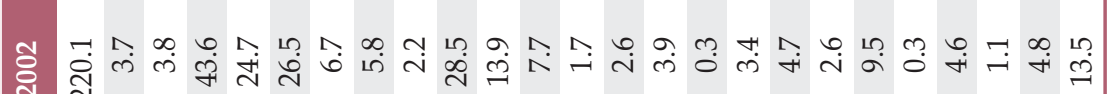

Бें

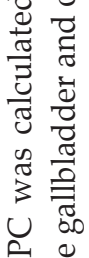

.

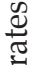

षै

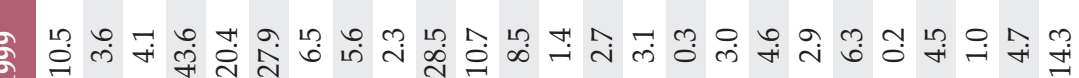

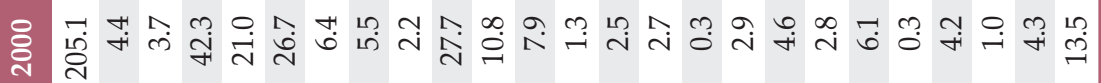

离䓪

$\cdot \vec{\square}$

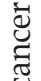

$\Xi$

$\frac{\infty}{\tilde{g}}$

巳

茪

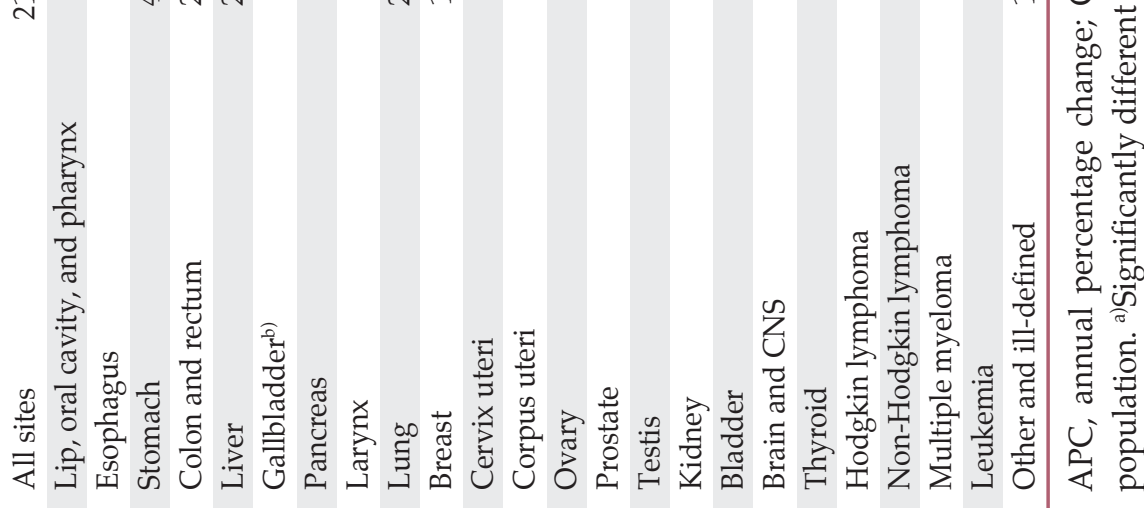




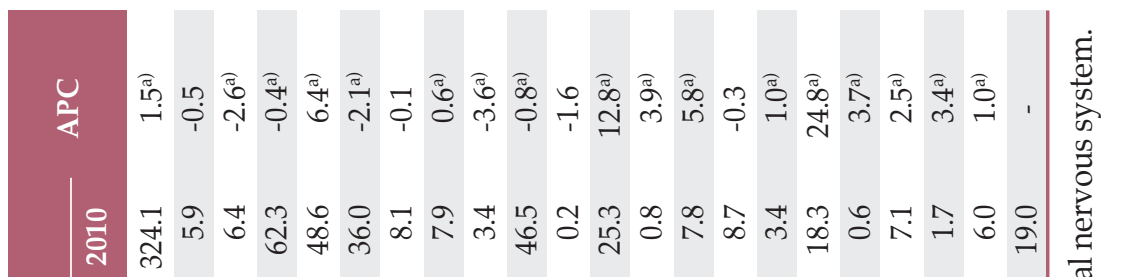

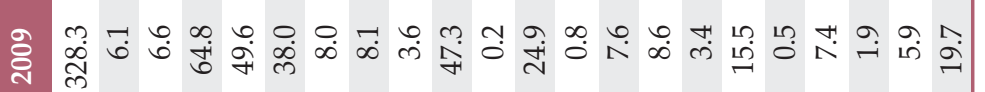

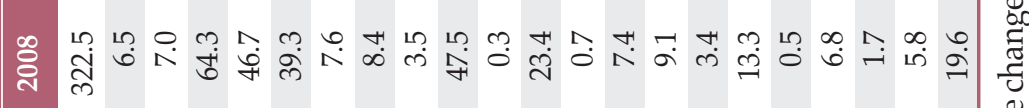

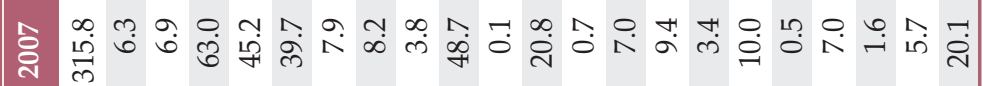

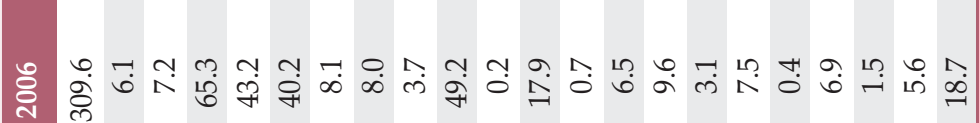

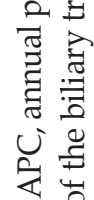

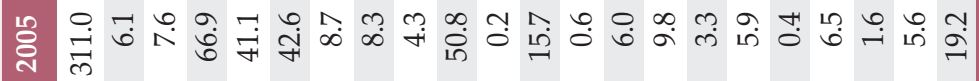
.ี่

ฮัँ

\# 䓀.

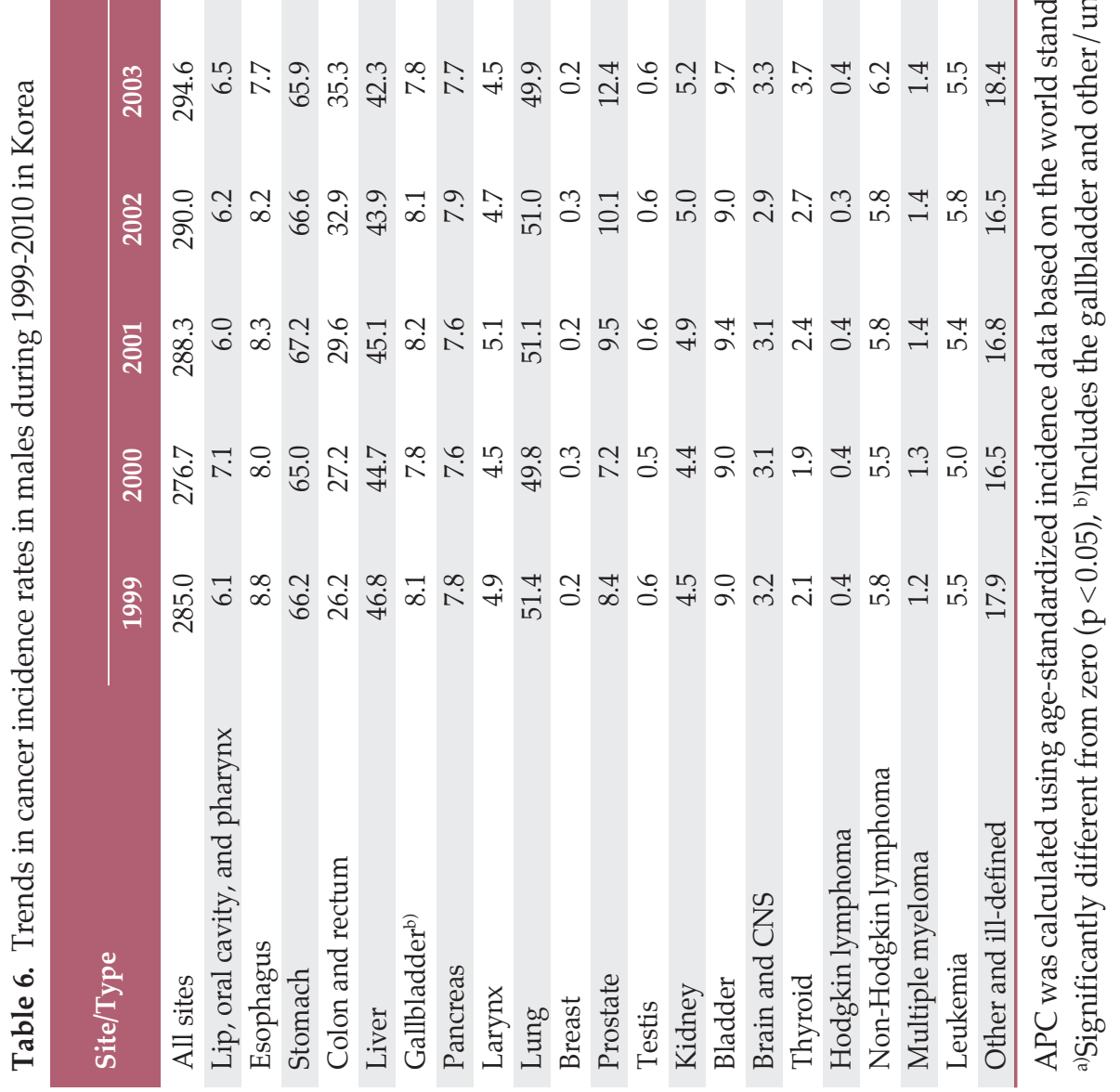

胥 营 


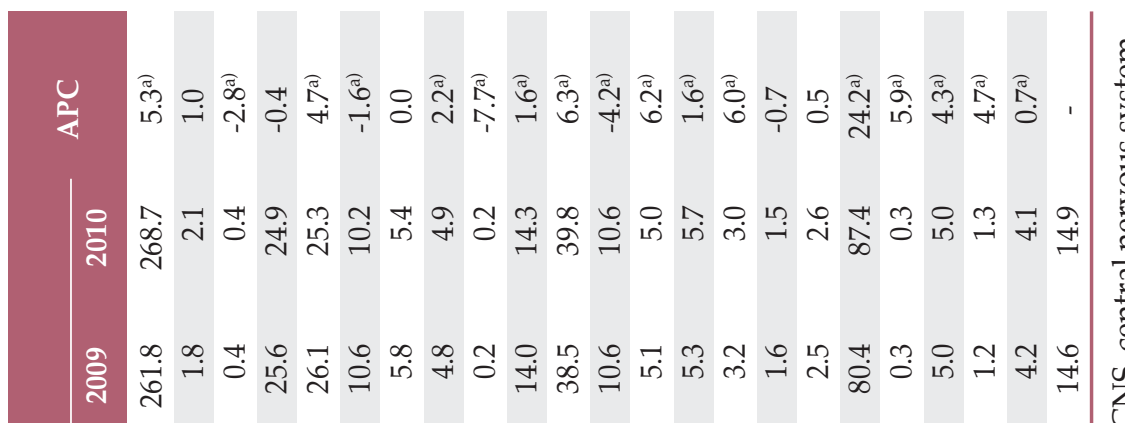

旁

m

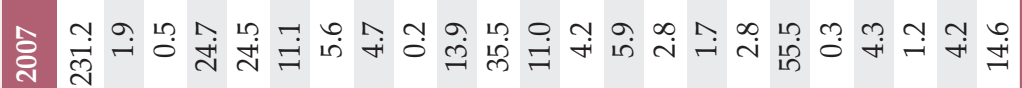

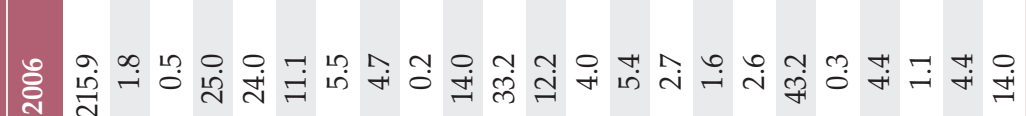

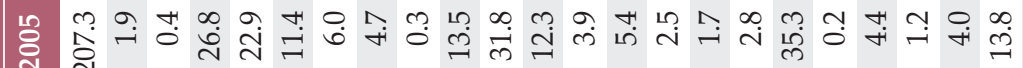

ฮ્ર

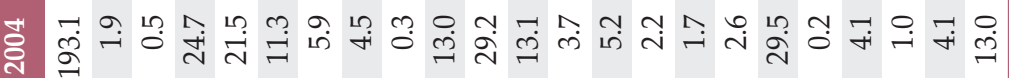

离

金 今ે

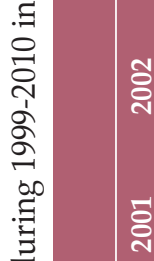

(a)

光

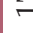

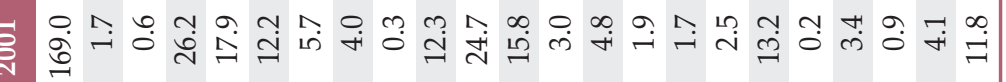

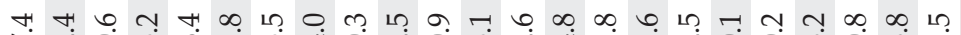
ถิ่

$\Xi$

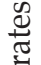

త్ర

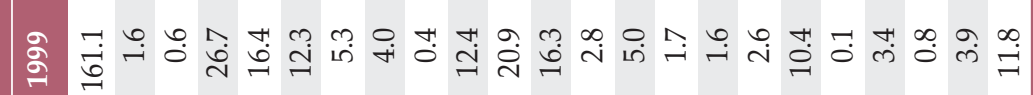

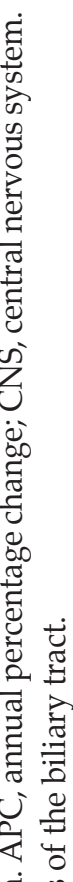
.]

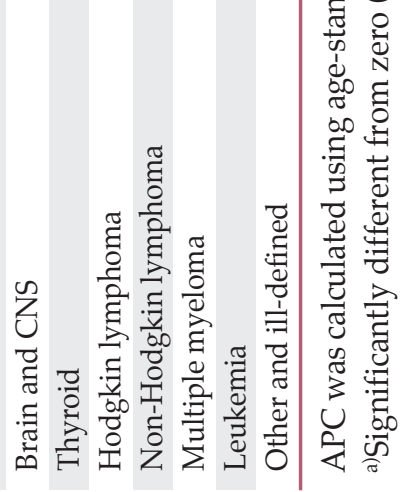


rectum (CR, 62.5; ASR, 48.6), lung (CR, 58.7; ASR, 46.5), liver (CR, 47.3; ASR, 36.0), and prostate (CR, 31.4; ASR, 25.3), which together accounted for $68.1 \%$ of all newly diagnosed cancers in 2010. In females, the most common cancer sites were the thyroid (CR, 119.6; ASR, 87.4), breast (CR, 57.1; ASR, 39.8), colon and rectum (CR, 40.8; ASR, 25.3), stomach (CR, 39.8; ASR, 24.9), lung (CR, 24.3; ASR, 14.3), and liver (CR, 16.5; ASR, 10.2), which together accounted for $70.8 \%$ of all newly diagnosed cancers. Thyroid cancer alone accounted for 30.1\% of incident cases $(n=29,790)$ in females in 2010 .

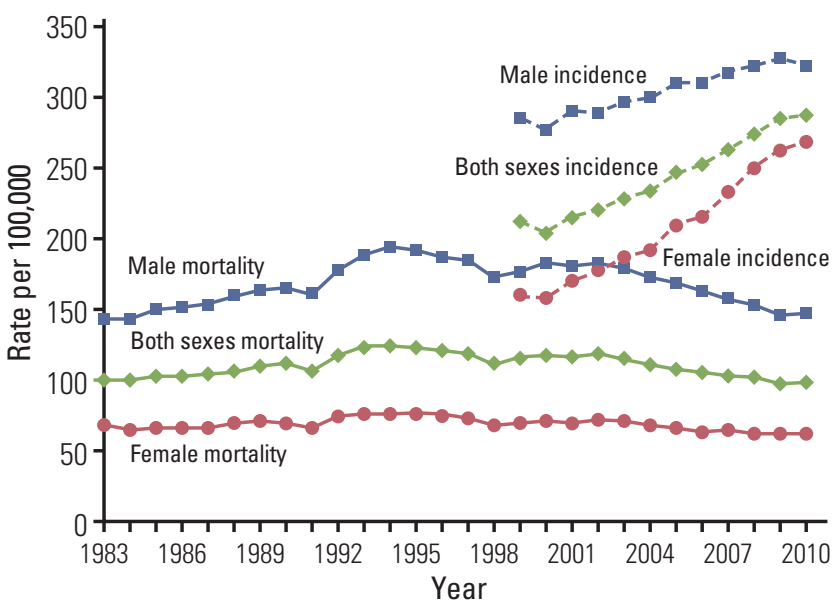

Fig. 1. Annual age-standardized cancer incidence and death rates for all sites during 1983-2010 in Korea by sex. Age standardization was based on the world standard population.

\section{Mortality}

In total, 72,046 cancer deaths were reported in Korea during 2010, accounting for $28.2 \%$ of all deaths (Table 3). In 2010, the CRs for all sites combined were 181.0 and 107.8 per 100,000 in males and females, respectively. The ASRs of all sites combined were 144.7 and 61.6 per 100,000 for males and females, respectively. Cancers of the lung, liver, stomach, and colon/ rectum were the most common fatal cancers, together accounting for about $61.8 \%$ of all cancer deaths in 2010 (Table 4).

In males, the five leading fatal primary cancer sites in 2010 were the lung (CR, 45.7; ASR, 36.6), liver (CR, 33.4; ASR, 25.8), stomach (CR, 26.1; ASR, 20.7), colon and rectum (CR, 17.3; ASR, 14.0) and pancreas (CR, 9.3; ASR, 7.4). In women, lung cancer (CR, 16.9; ASR, 9.1) was the most fatal cancer site in 2010, followed by the stomach (CR, 14.1; ASR, 7.8), colon and rectum (CR, 13.3; ASR, 7.3), liver (CR, 11.5; ASR, 6.6), and breast (CR, 7.5; ASR, 5.0).

\section{Trends in cancer incidence}

Tables 5-7 present the cancer incidence rates during 19992010 in Korea for all sites combined and for selected sites. The incidence for all sites combined increased by $3.3 \%$ annually (1.5\% in males, 5.3\% in females) from 1999 to 2010.

The rapid increase in cancer incidence is also illustrated in Fig. 1. As shown in Fig. 2, the incidence rates of colorectal and thyroid cancers have continued to increase in both sexes, as have those of prostate cancer in males and breast cancer in females. In contrast, the incidences of liver cancer in both sexes, lung cancer in males and cervical cancer in females
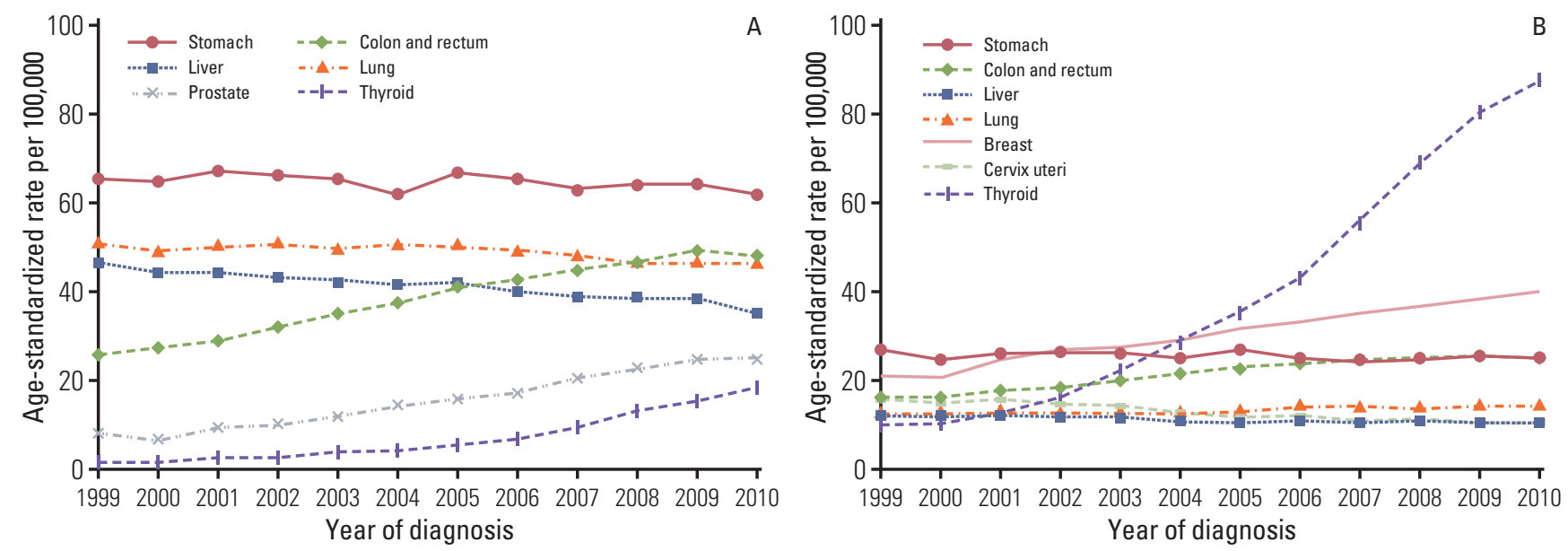

Fig. 2. Trends in age-standardized incidences of selected cancers during 1999-2010 in Korea by sex. Age standardization was based on the world standard population. (A) Male. (B) Female. 
Table 8. The five major sites of cancer incidence during 2010 in Korea by age group and sex

\begin{tabular}{|c|c|c|c|c|}
\hline \multirow{2}{*}{ Rank } & \multicolumn{4}{|c|}{ Age (yr) } \\
\hline & $0-14$ & $15-34$ & $35-64$ & $\geq 65$ \\
\hline \multicolumn{5}{|l|}{ Male } \\
\hline 1 & $\begin{array}{l}\text { Leukemia } \\
\qquad(5.1)\end{array}$ & $\begin{array}{l}\text { Thyroid } \\
(11.2)\end{array}$ & $\begin{array}{l}\text { Stomach } \\
(95.2)\end{array}$ & $\begin{array}{l}\text { Lung } \\
(455.0)\end{array}$ \\
\hline 2 & $\begin{array}{c}\text { Brain and CNS } \\
(2.5)\end{array}$ & $\begin{array}{l}\text { Leukemia } \\
\qquad(3.1)\end{array}$ & $\begin{array}{l}\text { Colon and rectum } \\
\qquad(72.1)\end{array}$ & $\begin{array}{l}\text { Stomach } \\
(433.2)\end{array}$ \\
\hline 3 & $\begin{array}{c}\text { Non-Hodgkin lymphoma } \\
(2.0)\end{array}$ & $\begin{array}{l}\text { Colon and rectum } \\
\qquad(2.7)\end{array}$ & $\begin{array}{l}\text { Liver } \\
(66.4)\end{array}$ & $\begin{array}{c}\text { Colon and rectum } \\
\qquad(340.6)\end{array}$ \\
\hline 4 & $\begin{array}{l}\text { Kidney } \\
(0.5)\end{array}$ & $\begin{array}{l}\text { Non-Hodgkin lymphoma } \\
(2.6)\end{array}$ & $\begin{array}{l}\text { Thyroid } \\
(42.9)\end{array}$ & $\begin{array}{l}\text { Prostate } \\
(274.1)\end{array}$ \\
\hline 5 & $\begin{array}{l}\text { Testis } \\
(0.3)\end{array}$ & $\begin{array}{c}\text { Stomach } \\
(2.6)\end{array}$ & $\begin{array}{l}\text { Lung } \\
\text { (42.5) }\end{array}$ & $\begin{array}{c}\text { Liver } \\
(199.3)\end{array}$ \\
\hline \multicolumn{5}{|l|}{ Female } \\
\hline 1 & $\begin{array}{l}\text { Leukemia } \\
\qquad(3.6)\end{array}$ & $\begin{array}{l}\text { Thyroid } \\
(59.9)\end{array}$ & $\begin{array}{l}\text { Thyroid } \\
(209.8)\end{array}$ & $\begin{array}{c}\text { Colon and rectum } \\
\text { (175.7) }\end{array}$ \\
\hline 2 & $\begin{array}{c}\text { Brain and CNS } \\
(1.7)\end{array}$ & $\begin{array}{l}\text { Breast } \\
(10.0)\end{array}$ & $\begin{array}{l}\text { Breast } \\
(106.5)\end{array}$ & $\begin{array}{l}\text { Stomach } \\
(162.2)\end{array}$ \\
\hline 3 & $\begin{array}{l}\text { Ovary } \\
(0.8)\end{array}$ & $\begin{array}{l}\text { Cervix uteri } \\
\quad(5.6)\end{array}$ & $\begin{array}{l}\text { Stomach } \\
(40.8)\end{array}$ & $\begin{array}{l}\text { Lung } \\
(121.5)\end{array}$ \\
\hline 4 & $\begin{array}{c}\text { Thyroid } \\
(0.7)\end{array}$ & $\begin{array}{c}\text { Stomach } \\
(4.3)\end{array}$ & $\begin{array}{l}\text { Colon and rectum } \\
\qquad(40.5)\end{array}$ & $\begin{array}{l}\text { Thyroid } \\
(85.0)\end{array}$ \\
\hline 5 & $\begin{array}{l}\text { Non-Hodgkin lymphoma } \\
(0.6)\end{array}$ & $\begin{array}{c}\text { Ovary } \\
(3.0)\end{array}$ & $\begin{array}{c}\text { Cervix uteri } \\
(23.0)\end{array}$ & $\begin{array}{l}\text { Liver } \\
(77.8)\end{array}$ \\
\hline
\end{tabular}

CNS, central nervous system.

have decreased. Stomach cancer incidence rates remained the same in males and females. One notable trend was the sharp (24.2\% annual) increase in the incidence of thyroid cancer in both sexes. Improvements in the sensitivity of diagnostic techniques for thyroid cancer, such as the advent of ultra- sound and fine-needle aspiration, have enabled the detection of subclinical disease. Therefore, the increased incidence of thyroid cancer may reflect the identification of previously undetected disease with these improved diagnostic techniques and increased screening rates, rather than a true
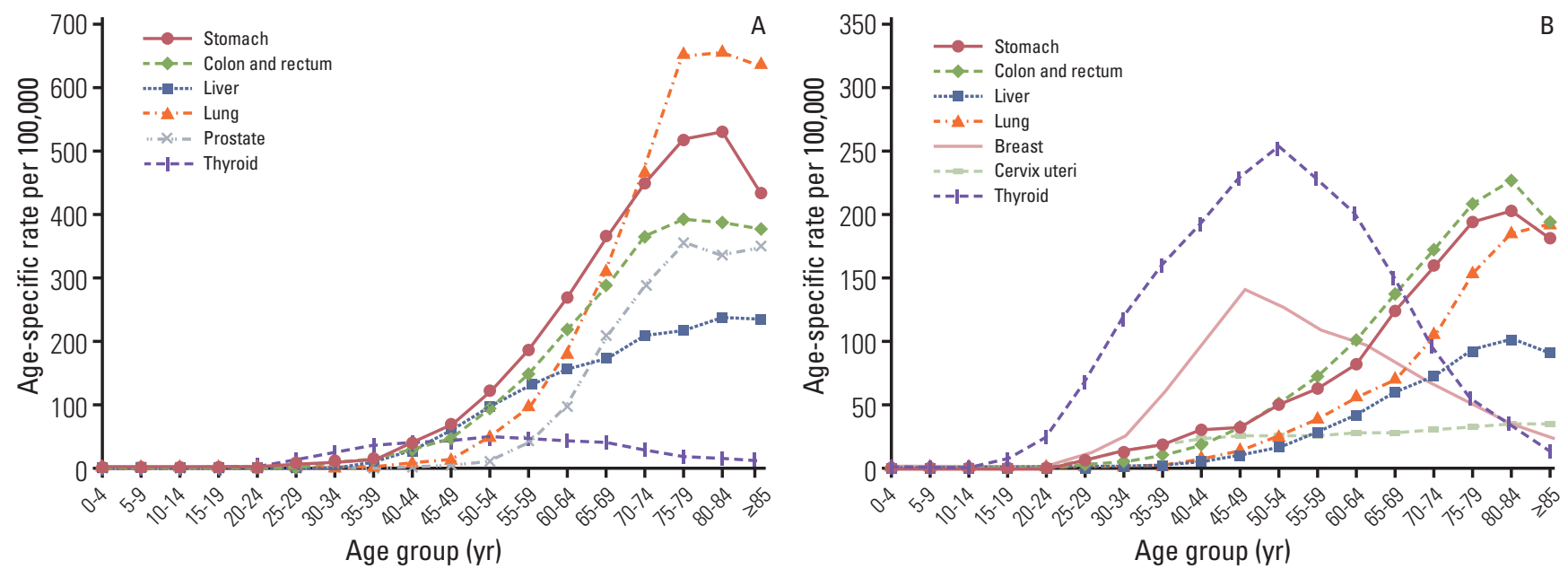

Fig. 3. Age-specific incidence rates of major cancers during 2010 in Korea. (A) Male. (B) Female. 


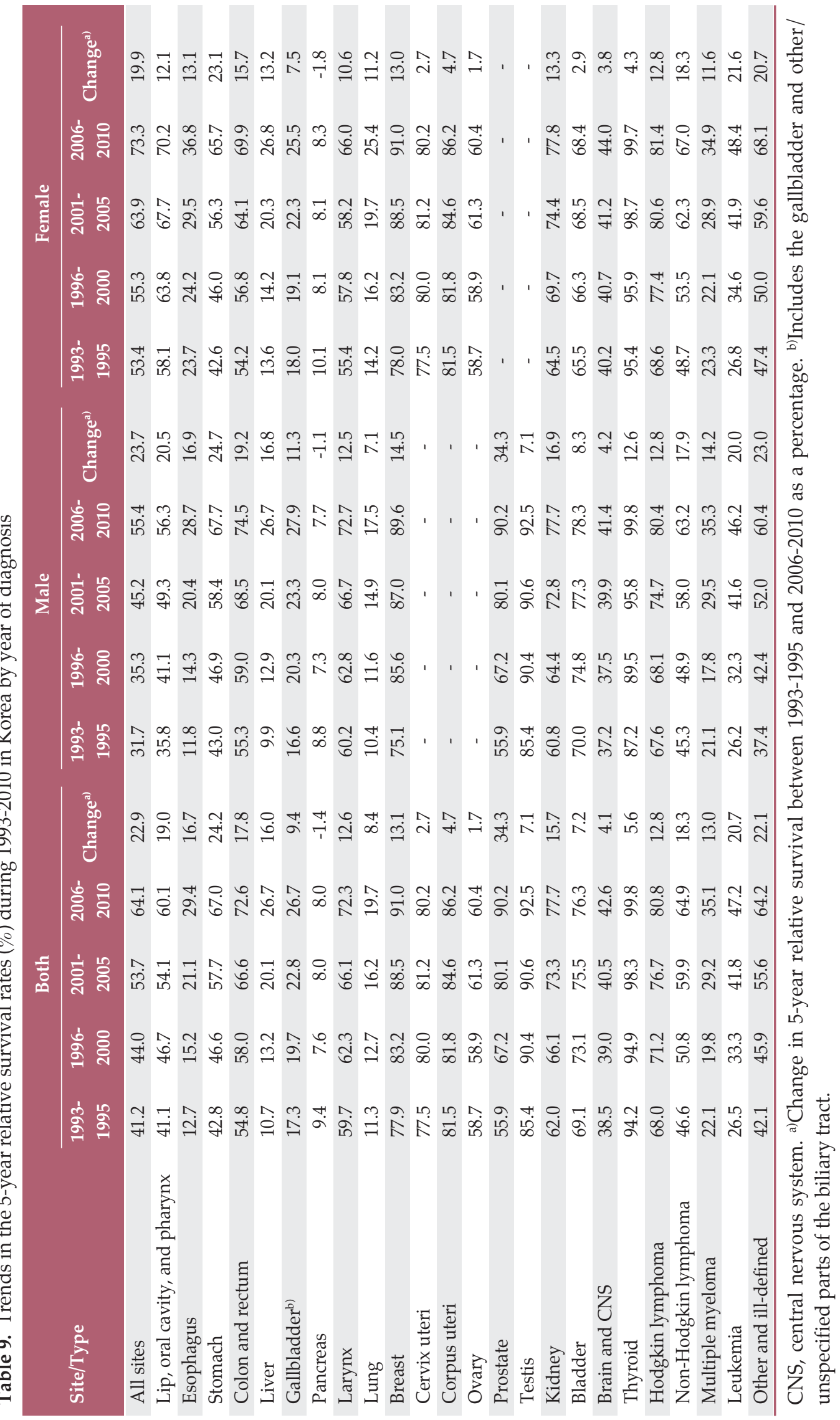



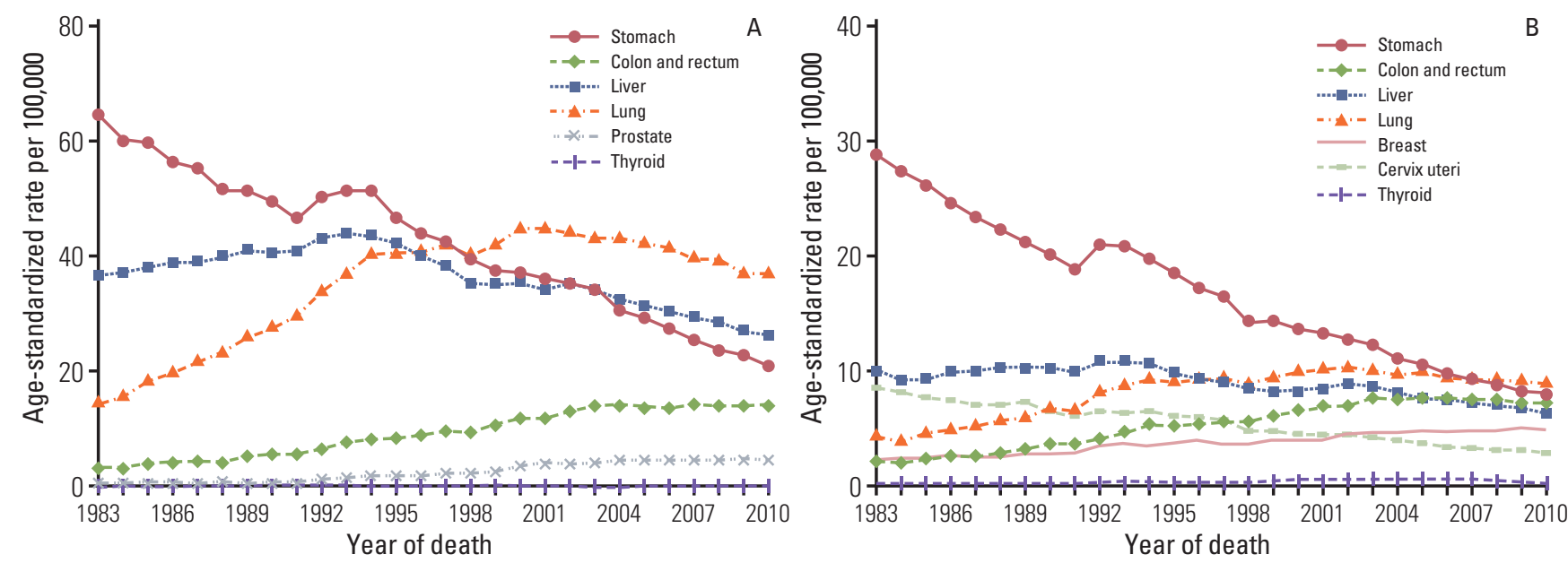

Fig. 4. Annual age-standardized mortalities of selected cancers during 1983-2010 in Korea by sex. Age standardization was based on the world standard population. (A) Male. (B) Female.

Table 10. Crude and age-standardized rates of cancer prevalence on January 1, 2011 in Korea by sex

\begin{tabular}{|c|c|c|c|c|c|c|}
\hline \multirow[t]{2}{*}{ Site/Type } & \multicolumn{3}{|c|}{ Crude prevalence rate per $100,000^{\mathrm{a}}$} & \multicolumn{3}{|c|}{$\begin{array}{l}\text { Age-standardized prevalenc rate } \\
\text { per } 100,000^{\text {b) }}\end{array}$} \\
\hline & Both & Male & Female & Both & Male & Female \\
\hline All sites & 1925.9 & 1739.0 & 2113.4 & 1370.9 & 1369.7 & 1446.7 \\
\hline Lip, oral cavity, and pharynx & 28.0 & 37.9 & 18.1 & 20.2 & 29.3 & 12.4 \\
\hline Esophagus & 12.6 & 22.8 & 2.5 & 8.8 & 18.0 & 1.5 \\
\hline Stomach & 340.6 & 451.7 & 229.1 & 236.4 & 349.3 & 144.6 \\
\hline Colon and rectum & 272.8 & 323.2 & 222.2 & 188.8 & 252.4 & 138.7 \\
\hline Liver & 86.9 & 130.3 & 43.4 & 62.5 & 100.1 & 28.9 \\
\hline Gallbladderc) & 24.8 & 25.4 & 24.1 & 16.9 & 20.0 & 14.6 \\
\hline Pancreas & 11.2 & 12.2 & 10.2 & 7.8 & 9.6 & 6.4 \\
\hline Larynx & 15.2 & 28.5 & 1.9 & 10.6 & 22.6 & 1.1 \\
\hline Lung & 87.3 & 115.2 & 59.4 & 60.5 & 90.8 & 37.4 \\
\hline Breast & 207.3 & 1.9 & 413.4 & 145.8 & 1.5 & 286.0 \\
\hline Cervix uteri & 77.2 & - & 154.6 & 53.9 & - & 104.5 \\
\hline Corpus uteri & 23.9 & - & 47.9 & 17.2 & - & 33.7 \\
\hline Ovary & 23.6 & - & 47.3 & 17.7 & - & 34.9 \\
\hline Prostate & 70.9 & 141.6 & - & 46.5 & 114.1 & - \\
\hline Testis & 3.6 & 7.1 & - & 3.3 & 6.4 & - \\
\hline Kidney & 40.5 & 54.6 & 26.4 & 29.5 & 42.3 & 18.4 \\
\hline Bladder & 43.9 & 71.4 & 16.5 & 29.5 & 56.5 & 9.4 \\
\hline Brain and CNS & 15.1 & 15.8 & 14.4 & 13.5 & 14.5 & 12.5 \\
\hline Thyroid & 350.7 & 105.2 & 596.9 & 253.0 & 76.9 & 427.5 \\
\hline Hodgkin lymphoma & 3.2 & 4.1 & 2.3 & 2.8 & 3.5 & 2.0 \\
\hline Non-Hodgkin lymphoma & 41.8 & 45.6 & 37.9 & 31.9 & 37.1 & 27.5 \\
\hline Multiple myeloma & 6.2 & 6.5 & 5.8 & 4.4 & 5.0 & 3.8 \\
\hline Leukemia & 24.6 & 27.2 & 22.1 & 24.2 & 27.0 & 21.5 \\
\hline Other and ill-defined & 114.1 & 110.9 & 117.2 & 85.1 & 92.6 & 79.2 \\
\hline
\end{tabular}

CNS, central nervous system. ${ }^{a}$ Crude prevalence rate: number of prevalent cases divided by the corresponding person-years of observation. Prevalent cases were defined as patients who were diagnosed between January 1, 1999 and December 31, 2010 and who were alive on January 1, 2011. Multiple primary cancer cases were counted multiple times, b)Age-adjusted using the world standard population, ${ }^{\mathrm{c}}$ Includes the gallbladder and other/ unspecified parts of the biliary tract. 


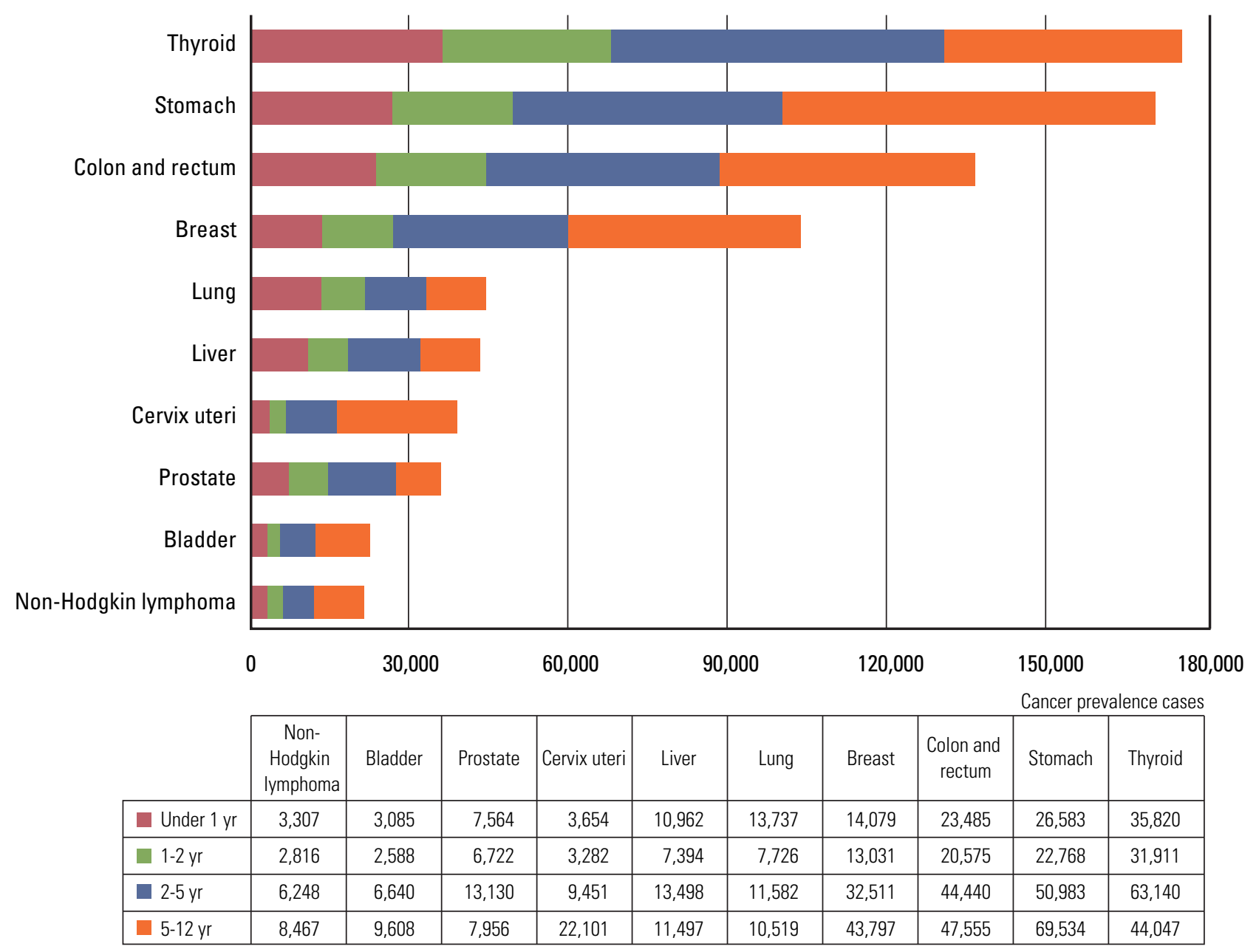

Fig. 5. Numbers of prevalent cases for major cancer sites on January 1, 2011 in Korea by time since diagnosis.

increase in the occurrence of thyroid cancer [14-17]. Furthermore, due to the construction of a 1999-2010 KNCI DB, the completeness of the Korea cancer registry data has improved gradually, and this may have contributed, in part, to the gradual overall increases in cancer incidence, particularly among elderly patients.

\section{Age-specific incidence rates}

Table 8 presents the most common cancer sites by sex and age group in 2010. Leukemia and thyroid cancer were the most common cancer in both sexes in subjects aged 0-14 and 15-34 years, respectively. For males, stomach cancer was the most common cancer in 35-64-year-olds, while lung cancer was more frequent among patients aged $\geq 65$ years. Thyroid cancer was the most common cancer in middle-aged Korean females (age, 35 to 64 years), and colorectal cancer was the most common cancer among older females ( $\geq 65$ years).

Fig. 3 shows the age-specific incidence rates for selected cancers in males and females in 2010. The data show that the incidences of stomach, lung, liver, and colorectal cancers increased gradually with age. Incidences of breast and thyroid cancers in females were highest in those in their late 40s and early 50s, respectively, and leveled off thereafter. This pattern is different from those in Western countries [18].

\section{Trends in cancer mortality}

Figs. 1 and 4 show the trends in cancer deaths for all sites combined and for selected sites. ASRs of mortality showed an annual decrease of $2.7 \%$ for all sites combined in both sexes since 2002. Lung cancer surpassed stomach cancer as the leading cause of cancer deaths in 1999 and is expected to account for $21.7 \%$ of all cancer deaths in 2010. The ASRs of mortality due to lung cancer have decreased slightly in males since 2001, but have increased in females. The ASRs of mortality due to stomach and cervical cancers have decreased continuously. Along with the significant increases 
in colorectal, prostate and female breast cancer incidence rates, the mortality rates of these cancers have also continued to increase.

\section{Survival rates}

Table 9 shows the 5-year relative survival rates for four diagnosis periods: 1993-1995, 1996-2000, 2001-2005, and 20062010. Patients who were diagnosed with cancer in the most recent period (2006-2010) had a 5-year relative survival rate of $64.1 \%$ for all sites combined in both sexes $(55.4 \%$ in males and $73.3 \%$ in females). When compared with earlier periods, notable improvements in the 5-year relative survival rates were observed for all sites combined. The higher cancer survival rate in females than in males may be partly explained by cancers common in females (e.g., thyroid, breast, and cervix cancers) having relatively good prognoses.

When examined by year of diagnosis and cancer site, the 5-year relative survival rates appeared to be higher for most major cancers in patients diagnosed during 2006-2010 compared with those diagnosed during 1993-1995, with the exception of pancreatic cancer. The greatest improvements were seen in prostate cancer, stomach cancer, non-Hodgkin lymphoma, leukemia, and colorectal cancer. The improving survival rates could be attributable to early detection and improved treatments $[19,20]$, but this requires further evaluation. Only pancreatic cancer showed no improvement in 5-year relative survival rate compared with 1993-1995. A lack of progress in early detection and treatment could explain the observed absence of improvement in the survival rate for pancreatic cancer [21].

\section{Prevalence rates}

Table 10 shows the cancer prevalent rates on January 1, 2011 in Korea by sex and cancer site. The CRs of cancer prevalence for all sites combined were 1,739.0 and 2,113.4 per 100,000 in males and females, respectively, and the ASRs of cancer prevalence for all sites combined were 1,369.7 and $1,446.7$ per 100,000 in males and females, respectively. In males, the five leading primary sites of cancer for prevalence were the stomach (CR, 451.7; ASR, 349.3), colon and rectum
(CR, 323.2; ASR, 252.4), prostate (CR, 141.6; ASR, 114.1), liver (CR, 130.3; ASR, 100.1), and lung (CR, 115.2; ASR, 90.8), which together accounted for $66.8 \%$ of all prevalent cancer cases. In females, the most common cancer sites were the thyroid (CR, 596.9; ASR, 427.5), breast (CR, 413.4; ASR, 286.0), stomach (CR, 229.1; ASR, 144.6), colon and rectum (CR, 222.2; ASR, 138.7), cervix (CR, 154.6; ASR, 104.5), and lung (CR, 59.4; ASR, 37.4), which together accounted for $79.3 \%$ of all prevalent cancer cases.

Fig. 5 shows prevalence by time since diagnosis with cancer. For all cancers combined, the 1-2-year prevalence represented $33.0 \%$ of all prevalent cases. The 1-2-year prevalence, as a percentage of the total prevalence, was highest for thyroid cancer $(21.4 \%)$, followed by stomach cancer $(15.6 \%)$ and colorectal cancer (13.9\%), which had high incidence rates and good prognoses. For all cancers combined, the 2-5-year and $>5$-year prevalences accounted for $31.6 \%$ and $35.4 \%$, respectively, of the total prevalence in both sexes. The longterm prevalences of lung and liver cancers were relatively low due to their low survival rates.

\section{Conflicts of Interest}

Conflict of interest relevant to this article was not reported.

\section{Acknowledgments}

This work was supported by a research grant from the National Cancer Center (no. 1310220), Republic of Korea. The authors are indebted to Korea Central Cancer Registry (KCCR)-affiliated hospitals, non-KCCR-affiliated hospitals, 11 regional cancer registries (the Busan, Daegu \& Gyeongbuk, Gwangju \& Jeonnam, Incheon, Daejeon \& Chungnam, Ulsan, Gangwon, Chungbuk, Jeonbuk, Gyeongnam and Jejudo cancer registries), the National Health Insurance Corporation and Statistics Korea for data collection.

\section{References}

1. Statistics Korea [Internet]. Daejeon: Statistics Korea; 2012 [cited 2013 Jan 4]. Available from: http://kostat.go.kr.

2. Yoon SJ, Bae SC, Lee SI, Chang H, Jo HS, Sung JH, et al. Measuring the burden of disease in Korea. J Korean Med Sci. 2007;22:518-23.

3. Jung KW, Park S, Kong HJ, Won YJ, Lee JY, Seo HG, et al. Cancer statistics in Korea: incidence, mortality, survival, and prevalence in
2009. Cancer Res Treat. 2012;44:11-24

4. Won YJ, Sung J, Jung KW, Kong HJ, Park S, Shin HR, et al. Nationwide cancer incidence in Korea, 2003-2005. Cancer Res Treat. 2009;41:12231.

5. Shin HR, Won YJ, Jung KW, Kong HJ, Yim SH, Lee JK, et al. Nationwide cancer incidence in Korea, 1999 2001: first result using the 
national cancer incidence database. Cancer Res Treat. 2005;37:325-31.

6. Ajiki W, Tsukuma H, Oshima A. Index for evaluating completeness of registration in population-based cancer registries and estimation of registration rate at the Osaka Cancer Registry between 1966 and 1992 using this index. Nihon Koshu Eisei Zasshi. 1998;45:1011-7.

7. Fritz A, Percy C, Jack A, Shanmugaratnam K, Sobin L, Parkin DM, et al. International classification of diseases for oncology. 3rd ed. Geneva: World Health Organization; 2000.

8. World Health Organization. International statistical classification of diseases and related health problems. 10th rev. Geneva: World Health Organization; 1994.

9. Segi M. Cancer mortality for selected sites in 24 countries (1950-1957). Sendai: Tohoku University School of Medicine; 1960.

10. Altekruse SF, Kosary CL, Krapcho M, Neyman N, Aminou R, Waldron W, et al. SEER cancer statistics review, 1975-2007. Bethesda, MD: National Cancer Institute; 2010.

11. National Cancer Institute. SEER ${ }^{*}$ Stat Program, version 6.6.1 [Internet]. Bethesda, MD: U. S. National Cancer Institute; [cited 2013 Jan 4]. Available from: http://seer.cancer.gov/seerstat/2010.

12. Ederer $\mathrm{F}$, Heise H. Instructions to IBM programmers in processing survival computations. Methodological note No. 10. Bethesda, MD: National Cancer Institute; 1959.

13. Paul Dickman [Internet]. Stockholm: PaulDickman.com; [cited 2010 Apr 14]. Available from: http://www.pauldickman.com.
14. Davies L, Welch HG. Increasing incidence of thyroid cancer in the United States, 1973-2002. JAMA. 2006;295:2164-7.

15. Enewold L, Zhu K, Ron E, Marrogi AJ, Stojadinovic A, Peoples GE, et al. Rising thyroid cancer incidence in the United States by demographic and tumor characteristics, 1980-2005. Cancer Epidemiol Biomarkers Prev. 2009;18:784-91.

16. Han MA, Choi KS, Lee HY, Kim Y, Jun JK, Park EC. Current status of thyroid cancer screening in Korea: results from a nationwide interview survey. Asian Pac J Cancer Prev. 2011;12:1657-63.

17. Kim SY. Study to provide evidence of health screening service for thyroid cancer. Seoul: National Evidence based Healthcare Collaborating Agency; 2012 [cited 2013 Jan 4]. Available from: http://www. neca.re.kr/.

18. Curado MP, Edwards B, Shin HR, Storm H, Ferlay J, Heanue M, et al. Cancer incidence in five continents. Vol. 9. Lyon: IARC Press; 2007.

19. Jung KW, Yim SH, Kong HJ, Hwang SY, Won YJ, Lee JK, et al. Cancer survival in Korea 1993-2002: a population-based study. J Korean Med Sci. 2007;22 Suppl:S5-10.

20. Gondos A, Bray F, Hakulinen T, Brenner H; EUNICE Survival Working Group. Trends in cancer survival in 11 European populations from 1990 to 2009: a model-based analysis. Ann Oncol. 2009;20:564-73.

21. Dickman PW, Adami HO. Interpreting trends in cancer patient survival. J Intern Med. 2006;260:103-17. 